\title{
Adoption and extent of conservation agriculture practices among smallholder farmers in Malawi
}

\author{
A. Ngwira, F.H. Johnsen, J.B. Aune, M. Mekuria, and C. Thierfelder
}

\begin{abstract}
Understanding factors affecting farmers' adoption of improved technologies is critical to success of conservation agriculture (CA) program implementation. This study, which explored the factors that determine adoption and extent of farmers' use of the three principles of CA (i.e., minimum soil disturbance, permanent soil cover with crop residues, and crop rotations), was conducted in 10 target communities in 8 extension planning areas in Malawi. The primary data was collected using structured questionnaires administered to individual households. Triangulation with key informant interviews, field observations, and interactive discussions with farmers and farmer groups provided information behind contextual issues underpinning the statistical inferences. From a total of 15,854 households in the study areas, it is estimated that $18 \%$ of the smallholder farmers had adopted CA, representing an area of about 678 ha (1,675 ac; $2.1 \%$ of all cultivated land). Land area under CA constituted about $30 \%$ of total cultivated land among adopters. A random sample of 151 adopters and 149 nonadopters proportional with respect to adoption rates was drawn from various communities and interviewed using structured questionnaires. A total of 30 key informant interviews were conducted with stakeholders including staff of Total Land Care, government extension workers, agroinput suppliers, and lead farmers. The first stage of the Heckman model showed that hired labor, area of land cultivated, membership to farmer group, and district influenced farmers' decisions to adopt CA. The second stage of Heckman model results suggested that total cultivated land, duration of practicing CA, and district influenced farmers' decisions to extend their land to CA. Our study can be used to show the agency and social structures that are likely to influence adoption and extent of CA. Future policy should address ways to provide access to information and long-term support to farmers to enable them to embrace the technology fully.
\end{abstract}

Key words: adoption—agency—conservation agriculture—smallholders—social structures

\begin{abstract}
Conservation Agriculture (CA) is increasingly promoted to overcome many of the problems associated with conventional agriculture, including soil degradation, high labor demands, and low and variable yields. Conservation agriculture is based on (a) minimal mechanical soil disturbance, (b) permanent organic soil cover by crop residues and/or cover crops, and (c) diversified crop rotations or associations with legumes (FAO 2013). Conservation agriculture tends to exclude the unsustainable parts (e.g., monocropping, tillage, and residue removal mainly through burning) of the conventional tillage (CT) system, thereby addressing soil erosion (Marongwe et al. 2011). Conservation agri-
\end{abstract}

It is estimated that no-tillage is practiced on 116 million ha (287 million ac; $2.4 \%$ of all cultivated land) worldwide, mostly on large scale commercial farms, with $46.8 \%$ of the total no-tilled land in South America, 37.8\% in the United States and Canada, $11.5 \%$ in Australia and New Zealand, 2.4\% in Asia, and $1 \%$ in Europe. Only a meager $0.3 \%$ of no-tillage is practiced in Africa, mostly on smallholder farms (Derpsch et al. 2010). While in the Americas and Australia the CA movement was largely driven by farmers (Ekboir 2003), in sub-Saharan Africa (SSA), including Malawi, smallholders generally do not have the resources or linkages that enable them to take hold of the reins of development. Smallholders are less able to invest in new equipment and are more risk averse than large-scale farmers. They generally manage complex farming systems, such as mixed crop-livestock systems (Wall 2007). In addition, smallholder farmers lack agricultural assets - they continue using hand hoes, have limited access to new information, and lack institutions supporting smallholder agriculture (Gowing and Palmer 2008; Nkala et al. 2011). Additional constraints to adoption of CA include removal of crop residues for fodder; lack of appropriate equipment, such as seed drills that can sow in an unplowed soil covered by crop residue mulch; nonavailability or prohibitively high costs of herbicides; and limited or nonexistent credit markets (Lal 2009). The mindset of farmers that tillage is needed for successful crop production is also critical (Wall 2007). The constraints mentioned above point to the need for different models of CA promotion

Amos Ngwira is a PhD student in the Department of International Environment and Development Studies, Norwegian University of Life Sciences in Aas, Norway. Fred H. Johnsen is a professor and director of the Department of Agricultural Sciences, Blæstad, Faculty of Applied Ecology and Agricultural Sciences in Elverum, Norway. Jens B. Aune is a professor in the Department of International Environment and Development Studies, Norwegian University of Life Sciences, in Aas, Norway. Mulugetta Mekuria is a senior scientist with the Socioeconomics Program, based at the International Maize and Wheat Improvement Centre (CIMMYT) Southern Africa Regional Office based in Harare, Zimbabwe. Christian Thierfelder is a conservation agriculture specialist with CIMMYT Southern Africa Regional Office based in Harare, Zimbabwe. 
in SSA, including Malawi, than those applied in other regions of the world.

Despite recent criticism on the suitability of CA as widespread recommendation for smallholders in SSA (Bolliger 2007; Giller et al. 2009), there is increased interest from donors, international research centers, nongovernmental organizations (NGOs), church organizations, and governments in promoting CA (Kassam et al. 2009). Adoption of CA has the potential to increase smallholder farms' resilience to rainfall variability, address soil degradation, and increase food production in an efficient, productive, and profitable manner (Hobbs et al. 2008; Rockström et al. 2009). Increasing the adoption of CA in maize (Zea mays L.) -based systems in Malawi is expected to have substantial potential impacts because of the extensive area of crop production and intensive use of hand hoes during ridging. Maize is planted on about 1.5 million ha (3.7 million ac), accounting for $85 \%$ of the total area of cultivated land. Under CA, farmers are expected to produce higher yields (Thierfelder et al.2013a) and save about 9 and $19 \mathrm{~d} \mathrm{ha}^{-1}$ (22 and 47 day ac ${ }^{-1}$ ) in land preparation and weeding, respectively, leading to more than double return to labor compared with CT practices (Ngwira et al. 2013). The expanded use of CA would have economic and environmental impacts on farmers in Malawi, including the potential for reduced labor days, soil erosion, and production costs.

Conservation agriculture systems were introduced to Malawi in 1998 by Sasakawa Global 2000 (SG2000), although it is likely that parts of this system were in place prior to the introduction of the plow/hand hoe and monoculture cropping systems. Conservation agriculture systems introduced by SG2000 were supported by the government of Malawi through a targeted input program funded by various donor organizations (Ito et al. 2007). A major driver in this first initiative was a set of management practices, e.g., improved recommendations on plant populations; herbicides for weed control (supported by Monsanto); and adequate fertilization, which was closely associated with the new emphasis on input support, which in turn possibly created input dependency by farmers. Maize grain yields increased over time due to greater use of inputs and higher plant densities (Ito et al. 2007). The approach was not sustainable since a lot of the SG2000 promotion was done in a linear top-down approach ignoring the need for active participation of farmers in iterative technology development through action research to facilitate colearning and coinnovation (Ekboir 2003; Hall et al. 2003; Wall 2007).

In 2004, CA was reintroduced in some target communities around Balaka (south), Dowa (central), and Mzimba (north) through collaborative efforts between the International Maize and Wheat Improvement Centre and Malawi Government Extension services. This work was later expanded to other districts in collaboration with the regional NGO Total Land Care (TLC) and Malawi government extension workers. The main concept in CA development was to initiate interactive communication of all relevant actors in the innovation system that identified soil degradation as the root problem of productivity decline. The network initially focused on discussions around demonstration plots of CA in each of the target communities, supported in succeeding years by farmer-led experiments around CA-oriented technologies.

Given the growing number of households experimenting with CA-oriented technologies or those affected by the spillovers, this study was conducted to gain a better understanding of CA practices in Malawi. While a number of programmes have been initiated to promote CA in smallholder farming systems, there is general paucity of literature that clarifies adoption and extent of farmers' use of the three principles of CA, i.e., minimum soil disturbance, permanent soil cover with crop residues, and crop rotation. Understanding the drivers of this change and documenting and assessing the factors influencing the dynamics of the adoption process are very critical components in explaining adoption. This study explores the factors that determine the adoption of CA and explains the variation in the extent of CA among different households. The findings of this study are envisaged to make important contribution to CA promotion policies in Malawi and other developing countries, particularly in southern Africa.

Theoretical Perspectives. This study draws on the adoption theory to explain factors influencing farmers' decisions to embark on CA. Two main paradigms can be distinguished in the theory of adoption of agricultural innovations by smallholders: individualistic and constructivist perspectives (Leeuwis and Ban 2004). Rational choice theory is compatible with individualistic perspective and assumes that the farmer is an individual choosing to adopt new technology from rational calculations, with given sets of ranked preferences and full information access. Neoclassical economic theory based on this individualistic perspective can be classified as the economic constraints model, the diffusion of innovations model, and the adopter perception model (Adesina and Zinnah 1993).

The economic constraints model assumes that individuals strive for profit or utility maximization but observed patterns of adoption are determined by the asymmetrical distribution of resource endowments among individuals (Adesina and Zinnah 1993; Negatu and Parikh 1999). While the economic constraints model recognizes the importance of profitability and economic constraints (access to capital, learning costs associated with innovation, or risk), it fails to conceptualize the social dimensions of knowledge, information, communication, and rationality (Leeuwis and Ban 2004).

The diffusion of innovations model identifies access to information as the key factor determining adoption decisions (Rogers 2003). In this model, adoption of innovations follows a sequence of stages: knowledge, persuasion, decision, implementation, and confirmation. The use of agricultural innovation among farmers and the resulting social change in the developed world has mainly been understood from the diffusion of innovations perspective. This model sees changes as a linear process in which innovations generated by agricultural research are passed down to farmers through extension agents. Thus agricultural research is the source of innovation, extension agents act as modes of communication, and farmers are recipients of the innovation. Farmers' rationality is judged either by adopting or rejecting innovations which are seen as the outcome of an innovation-decision process (Mwaseba et al. 2006). In this way, the innovation-decision process is reduced to a dichotomy by simply involving adoption and rejection based on the idea that research-generated innovations are finished products (Douthwaite 2002). Although the diffusion of innovations model recognizes that adoption is a multistage process of collecting information, revising opinions, and reassessing decisions (Feder et al. 1985), it fails to take into account the individual characteristics of the adopter. 
The adopter perception model includes the perception of the individuals in explaining adoption. This perception is determined by personal characteristics (human values, education, and experience); physical factors of the land; and institutional factors, e.g., raising awareness through extension (Lynne et al. 1988). Thus, based on individualistic perspectives, the adoption of innovations is portrayed as relating to an individual without paying much attention to coordination between interdependent actors. However, these schools of thought that are based on individualistic perspectives do not adequately address the role of social learning in the adoption of innovations.

Social learning is compatible with the constructivist perspective and is described as a key mechanism for arriving at more desirable futures and as a "third way of getting things done" that stands in sharp contrast to instrumental modes of thinking underlying individualistic perspectives (Röling 2002). Social learning theoretical perspective posits that people learn by observing the behaviour of others (Bandura 1977). The sociopolitical nature of the learning process implies that knowledge and perceptions tend to be socially constructed.

Social construction implies that socially created values and norms constitute the foundation for human behaviour and adaptation. Social construction sees an individual as a member of a society whose views are formed through primary and secondary socialization processes (Berger and Luckmann 1967). Different people may need different forms of support in reaching similar conclusions. Some farmers like to discuss problems and experiences in a study group or group meeting, while others tend to avoid group sessions and prefer to figure out things by themselves or through bilateral contacts only. Changing from one technology to another will require "double loop learning" (Leeuwis and Ban 2004); a farmer needs to learn how to deal with new management and a new network of people and institutions. In such situations, feedback plays an important role in shaping human practices. Feedback is information that is obtained about the outcomes, characteristics, and/or consequences of our actions, and it helps us to evaluate these.

Since society is socially organized formally and informally, farmers' use of a particular resource can also be understood by interviewing groups of farmers or representatives of organizations. Constructivist perspective sees adoption of an innovation as a continuous social process in which learning of new practices occurs both in formal and informal settings through sharing information, observation, imitation, or as a normative action (Bandura 1977). Furthermore, decisions take place within limits of information and constraints existing in society (Long and Long 1992).

The adoption of CA can be seen as a farmer accepting an innovation (temporarily or permanently). The adoption paradigm illustrates that adoption of an innovation is not a characteristic of an individual alone but encompasses a set of phases or levels, such as cognitive, normative, and action-oriented, that govern it (Prager et al. 2011) Recognizing these levels will aid in understanding the prerequisites necessary for successive steps that ultimately lead to sustainable adoption. Institutional factors, such as policies and subsidies, can facilitate the adoption process by omitting the cognitive phase. For example, financial incentives may induce farmers to adopt CA by compensating for anticipated losses even though the farmer may not be convinced that there is a need to adopt the innovation. This therefore raises concerns about the sustainability of the adoption decision.

\section{Materials and Methods}

Study Areas. This study was conducted in 10 target communities in 8 extension planning areas in Malawi (figure 1). The following districts were used: Balaka, Dowa, Machinga, Nkhotakota, Salima, and Zomba. These communities were selected because they are where CA technologies have been tested since 2004 and represent a wide range of biophysical and socioeconomic conditions, including organizations providing support services to farmers. All study areas are characterized by unimodal rainfall patterns with a rainy season from November to April. The dominant soil types found in these extension planning areas are chromic Luvisols, haplic Lixisols, eutric Fluvisols and Cambisols, and some alluvial soils (WRB 1998) (table 1). The dominant cropping systems include maize-pigeonpea (Cajanus cajan L.) intercropping in Balaka, Machinga, and Zomba while Dowa, Nkhotakota, and Salima districts are dominated by crop rotations. Maize remains the major staple crop occupying the majority of land area under cultivation in all study areas. Apart from maize, farmers in
Balaka, Nkhotakota, and Salima plant cotton (Gossypium hirsutum L.) and cassava (Manihot esculenta Crantz). Groundnut (Arachis hypogaea) is largely grown in Salima, Nkhotakota, and Dowa with burley tobacco, flue-cured tobacco, fire-cured tobacco and Malawi oriental tobacco, mainly grown in Salima and Dowa districts. Nkhotakota is the only district where farmers allocate part of their land to growing rice (Oryza sativa L.).

At the time of the household survey study, about $18.5 \%$ of smallholder farmers in the study areas were practicing CA on an average area of 0.2 ha $(0.5 \mathrm{ac})$ out of average landholding size of 2.1 ha $(5.2 \mathrm{ac})$ for the whole sample (table 2). Conservation agriculture was estimated to be practiced on $2.1 \%$ of the total cultivated land $(32,486$ ha [80,275 ac]) in the 2009 to 2010 cropping season. There were significant differences between locations in land area allocated to CA, with households in Dowa, Nkhotakota, and Salima districts allocating more land area under CA than households in Balaka, Machinga, and Zomba.

Description of the Conservation Agriculture Technologies. The CA systems being promoted and adopted by farmers in the study areas include the following: (a) minimal soil disturbance, (b) permanent ground cover by using previous year's crop residues, (c) intercropping maize with grain legumes such as cowpea (Vigna unguiculata L.) in central Malawi and pigeonpea in southern Malawi, (d) integration of agroforestry tree species into CA systems, and (e) crop rotations. Minimal soil disturbance involves direct seeding of crops using dibble stick (Ngwira et al.2013) without construction of new ridges. Weeds are controlled using herbicides and light hoe weeding. Crop residues are applied on the soil surface in the dry season soon after harvesting. Farmers aim for at least 30\% soil cover and often use maize stover. The mulch cover helps in reducing soil evaporation thereby conserving soil moisture, suppressing weeds through shading, and improving soil fertility by decomposition. Crop rotation is important in improving soil fertility, breaking the life cycle of pests and diseases, controlling weeds, and also reducing the risk of total crop failure on the farm.

Sampling Procedure and Data Collection. The primary data was collected using structured questionnaires administered to farm households, key informant interviews, field observations, and interactive discussions 


\section{Figure 1}

Sites of conservation agriculture adoption study in Malawi.

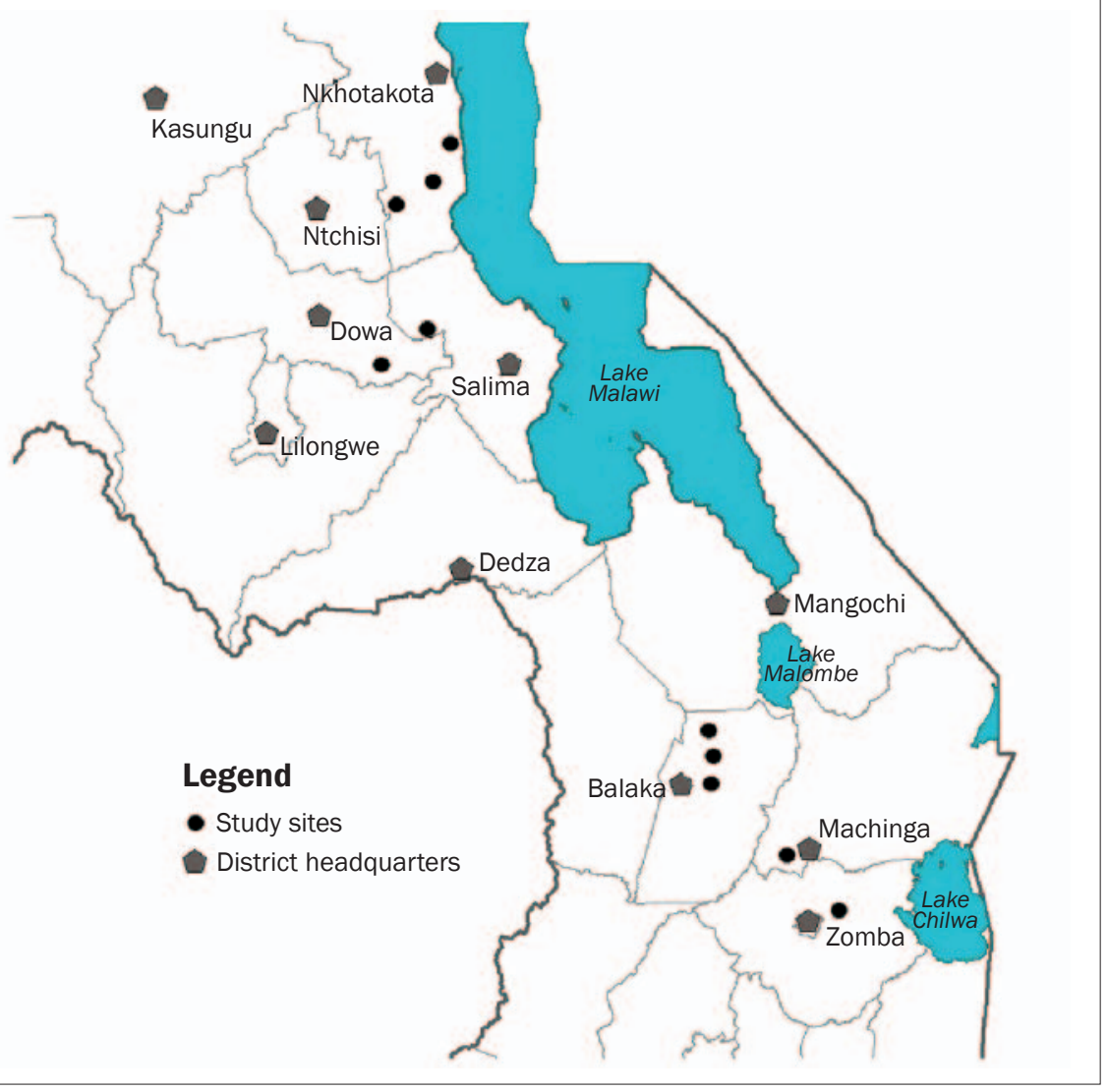

with farmers and farmer groups. Published and unpublished reports on general agricultural production and overview of CA in the study areas formed secondary data. Case studies were conducted in all study areas a drivers of adoption of CA as well as variants and extent of CA. A structured questionnaire was designed to capture data on farmers' production activities and production-related year prior to the study to understand major socioeconomic characteristics. Prior to the interviews, the questionnaire was pretested to control validity, and modifications were made where necessary to enhance its utility in addressing the relevant issues. The household survey was conducted between May and June of 2010 by five trained enumerators who administered the questionnaire to the household head or any other senior member whenever the household head was not present at the time of the interview.

Two categories of farmers were included in the household sample: farmers who are currently using CA (adopters) and farmers who have never tried CA before but have been exposed to CA technology (nonadopters). Adopters included farmers hosting CA demonstration plots and farmers adopting CA without participating in CA demonstration plots. Adopters also included full adopters (farmers adopting all the three principles of CA) and partial adopters (farmers adopting only two of the CA principles, e.g., minimum soil disturbance and crop residue retention as surface mulch but no crop rotation). A random sample of 300 households, proportional with respect to adoption rates was drawn from a total of 15,854 households in the study areas (table 2), of which 151 were adopters and 149 nonadopters. A total of 30 key informant interviews were conducted with stakeholders including staff of TLC, government extension workers, local leaders, and lead farmers (early adopters). Purposive sampling was used in the selection of key

\section{Table 1}

Study site descriptions. Soil type is based on Food and Agriculture Organization of the United Nations classification (WRB 1998). A global positioning system was used to take geographical positions of farmers' fields hosting conservation agriculture on farm trials, and an average value of latitude, longitude, and altitude in each community is reported. The same geographical positions were used to identify the dominant soil type in each community by interpolating the points on soil map of Malawi using Food and Agriculture Organization of the United Nations classification. Rainfall was recorded by extension workers using a rain gauge in the center of each community hosting the trials.

\begin{tabular}{lllllll}
\hline District & Community & $\begin{array}{l}\text { Rainfall } \\
(\mathbf{m m})\end{array}$ & Latitude & Longitude & $\begin{array}{l}\text { Altitude } \\
\text { (m above } \\
\text { sea level) }\end{array}$ & Soil type \\
\hline Balaka & Herbert & 684 & -14.88 & 35.04 & 635 & Chromic Luvisols \\
Balaka & Lemu & 862 & -14.79 & 35.00 & 720 & Chromic Luvisols \\
Balaka & Malula & 717 & -14.96 & 34.98 & 605 & Predominantly Eutric Fluvisols \\
Dowa & Chipeni & 883 & -13.76 & 34.05 & 1,166 & Chromic Luvisols \\
Machinga & Matandika & 874 & -15.17 & 35.28 & 688 & Cambic Arenosols \\
Nkhotakota & Linga & 1,237 & -15.03 & 34.94 & 629 & Alluvial soils \\
Nkhotakota & Mwansambo & 1,371 & -13.29 & 34.13 & 632 & Haplic Lixisols \\
Nkhotakota & Zidyana & 1,429 & -13.23 & 34.24 & 535 & Predominantly Haplic Luvisols \\
Salima & Chinguluwe & 1,241 & -13.69 & 34.24 & 657 & Eutric Cambisols \\
Zomba & Songani & 1,371 & -15.34 & 35.39 & 791 & Ferruginous, Ferrallitic soils
\end{tabular}




\section{Table 2}

Adoption rate (\%) of conservation agriculture (CA), average landholding size (ha), average area under CA (ha), total cultivated land (ha), and estimated land under CA (ha) in selected districts in central and southern Malawi. The information used to calculate adoption rates was obtained from field staff who keep records of adopters. Total number of farming households was solicited from government extension workers who conduct household listing every year as part of their work.

\begin{tabular}{lcllcc}
\hline Location & $\begin{array}{l}\text { Adoption } \\
\text { rate }\end{array}$ & $\begin{array}{l}\text { Average } \\
\text { landholding } \\
\text { size }\end{array}$ & $\begin{array}{l}\text { Average } \\
\text { land area } \\
\text { under CA }\end{array}$ & $\begin{array}{l}\text { Total } \\
\text { cultivated } \\
\text { land (ha) }\end{array}$ & $\begin{array}{l}\text { Estimated } \\
\text { land under } \\
\text { CA (ha) }\end{array}$ \\
\hline Balaka & 1.54 & 1.71 & 0.14 & 8,883 & 11 \\
Machinga & 2.20 & 0.89 & 0.08 & 1,134 & 2 \\
Zomba & 0.90 & 1.28 & 0.14 & 3,141 & 3 \\
Dowa & 41.25 & 2.04 & 0.28 & 3,427 & 197 \\
Nkhotakota & 27.00 & 2.77 & 0.31 & 12,066 & 368 \\
Salima & 38.99 & 4.04 & 0.26 & 3,834 & 97 \\
\hline Average/total* & 18.65 & 2.12 & 0.20 & 32,485 & 678 \\
\hline
\end{tabular}

* Indicates average values for average land holding size, adoption rate, and average land areas under CA, while it denotes total values for total cultivated land and estimated land under CA.

informants so as to have participants who are known to have experiences and opinions on the topics for discussion. Field observations provided information that could not be captured using the questionnaire and key informant interviews. Field observations were also a tool used in cross checking the information gathered by the questionnaire. Field observations and informal discussions with farmers and key informants were continuous processes during the entire duration of the research.

Modeling Decision to Adopt Conservation Agriculture and Its Extent. We modeled the sequential decisions to adopt CA and the extent of its adoption, measured as area allocated to CA. The rationale behind this is that farmers first decide whether to adopt CA or not (also after risk considerations) and then decide how much land to allocate. While the decision to adopt can be modeled in a single-equation, modeling the extent of adoption in a single-equation creates a selection bias. The extent of CA adoption is conditional on first adopting CA, and therefore, there is need to control for the factors that affect adoption before assessing determinants of extent of adoption. Single-equation approaches to these types of problems fail to capture the logical two-step decision process that potential participants undertake (Lohr and Park 1995). We therefore employ a twostep discrete-continuous modeling approach to capture this decision making. Specifically, we use a two-step Heckman sample selection-correction model (Heckman 1979) where we first model the decision to adopt $\mathrm{CA}$ and then, conditional on CA adoption, assess the determinants of extent of adoption in the second stage.

The decision to adopt CA is treated as a dichotomous choice. The household decision is made based on the utility that is derived from the chosen agricultural technique. The household chooses between using CA and CT. This choice is not exclusive since part of the land can be used for CT and part for CA. Therefore, the choices faced by the farmer are represented in this analysis as using $\mathrm{CT}$ or CA exclusively or using CA and $\mathrm{CT}$ in combination.

We employ a utility maximization model assuming that farm households choose a set of agricultural practices based on the resources that are available to them, the knowledge they possess, and the constraints that limit these activities (Rahm and Huffman 1984; Adesina and Zinnah 1993). It is assumed that economic agents, including smallholder farmers, adopt new agricultural technologies only when the perceived utility or net benefits from using such a technology is significantly greater than in the existing technology. Although the utility that is derived from the agricultural choices is not directly observable, differences among farmers in the nonobservable underlying utility function can be modeled through farm characteristics and specific technology characteristics. The unobservable underlying utility function is represented by $U_{i t}\left(M_{i}, T_{i}\right)$, where $i$ represents household and $t$ represents the technology choice $(t$ equals one when any level of CA is employed, and $t$ equals two when farmer uses CT only). The utility is derived from the observable farm and household characteristics, $M$ (including farm size, average age, and education of household heads), and from the observable technology characteristics, $T$ (including yield, income, and the labor-leisure ratio), where technology refers to the agricultural methods used by the household.

The family chooses $U_{i 1}$ and $U_{i 2}$, depending on which technology yields the greatest utility. Therefore, the utility ranking of the chosen technology is estimated from the vector of observable farm characteristics as follows:

$U_{i t}=\mathrm{a}_{i} F_{i}\left(X_{i}\right)+\theta_{i t} \quad[t=1,2 ; i=1,2, \ldots n],(1)$

where $\theta_{i t}$ is a disturbance term having zero mean.

The $i^{\text {th }}$ household will choose to use CT if $U_{1 i}<U_{2 i}$ or if the latent variable $Y^{*}=U_{i 2}$ $-U_{i 1}>0$, and it will choose CA when $U_{1 i}>$ $U_{2 i}$ or if the unobservable latent variable $Y *$ $=U_{i 1}-U_{i 2}>0$ :

$Y_{i}=\left\{\begin{array}{l}\text { 1if } U_{1 i}>\mathrm{U}_{2 i} \\ \text { Oif } U_{1 i}<\mathrm{U}_{2 i}\end{array}\right.$,

where one indicates that CA is adopted and zero indicates that CT is adopted. The probability that the farmer adopts CA or that $Y_{i}$ equals one is the probability that the utility gained from CT is less than the utility gained from CA (Adesina and Zinnah 1993; Caviglia and Kahn 2001).

Equation 1 is not restricted to be linear. The exact distribution of $F$, and hence estimation, depends on the distribution of the error term. For the purpose of this analysis, the error term is assumed to be normal, making the estimation of the probability possible using a probit model.

The second stage of the model involves the estimation of the extent of adoption once the decision is made to adopt CA by the $i^{\text {th }}$ household. Evaluating equation 3 the functional form of $F$ is specified with a Heckman model, where $u_{i}$ is an independently normal distributed error term with zero mean and constant variance $\sigma$.

$\begin{array}{ll}Y_{i}=X \beta & \text { if } i *=X_{2 i} \beta_{2}+\mu_{i}>H, \\ Y_{i}=0 & \text { if } i *=X_{2 i} \beta_{2}+\mu_{i} \leq H,\end{array}$

where $Y_{i}$ is the probability of adopting CA, $i *$ is the unobservable latent, $H$ is unobservable threshold value, and $X_{2 i}$ are the independent variables that are used to explain the extent of adoption decisions.

The Heckman model combines the above two stages simultaneously and is specified as 
$C_{i}=Z_{i} \varphi+\varepsilon_{i}$ (CA adoption)

$Y_{i}=X_{i} \beta+\mu_{i}$ (extent of CA adoption), (4b)

where, $C_{i}$ is a dummy variable for CA adoption, $Z_{i}$ is a vector of determinants of CA adoption, $Y_{i}$ is the extent of CA adoption (proportion of land area under CA), $X_{i}$ is a vector of determinants of CA extent of adoption, $\theta$ and $\beta$ are vectors of parameters to be estimated, and $\varepsilon_{i}$ and $\mu_{i}$ are error terms.

According to Heckman (1979), for the estimated parameters of equation $4 \mathrm{~b}$ to be efficient there should be no correlation between the two error terms $\left(\varepsilon_{i}\right.$ and $\left.\mu_{i}\right)$. However, sample selection bias results in a nonzero correlation between the two errors. To correct for this selection bias, the Heckman model first estimates the first stage (4a) to obtain a sample selection indicator called Inverse Mills Ratio (IMR). The IMR measures the covariance between the two errors and, as will be noted later, is an indicator of whether there is significant sample selection bias or not. The predicted errors and the IMR in the first stage are then entered into the second stage (4b) together with the $X_{i}$ vector of regressors. Thus, we respecify equation $4 \mathrm{~b}$ as

$Y_{i}=X_{i} \beta+\theta \lambda_{i}+\eta_{i}$

where, $Y_{i}, X_{i}$, and $\beta_{i}$ are as previously defined; $\lambda$ and $\theta$ are IMR and its parameter estimate respectively; and $\eta_{i}$ is a sample selection-corrected error term.

As indicated earlier, the IMR parameter estimate is used to test for sample selection bias. The null hypothesis for sample selection bias is that $\theta=0$, i.e., the IMR collapses to zero hence there is no sample selection bias. Therefore, when the IMR is significant, the null hypothesis is rejected (i.e., there is significant sample selection bias). On the other hand, when the IMR is not significant, the null hypothesis of sample selection bias is not rejected implying that a single-equation ordinary least squares (OLS) estimation of equation $4 \mathrm{~b}$ would yield efficient estimates. We used Stata econometric package to estimate the Heckman model.

Selection of Explanatory Variables. The selected potential independent variables for inclusion in the economic models were based on a model of farmer adoption that includes market incentives, biophysical conditions, risk and uncertainty, household preferences, and resource endowment (Mercer and
Pattanayak 2003). Some of the selected variables were based on a review and synthesis done by Knowler and Bradshaw (2007) and those variables compatible with $\mathrm{CA}$ as defined by the Food and Agriculture Organization of the United Nations (2013). These selection criteria helped in identifying variables that reflect the particular conditions of individual study areas since there are few if any universal variables that regularly explain the adoption of CA. A total of 13 independent variables were included in the first stage of the model and 9 in the second stage of the model.

Age is a continuous variable and was used in this study to determine its performance, particularly to the Malawi situation. It is hypothesized that older farmers with more farming experience are more likely to adopt CA and allocate more land to CA. Such results have been reported linking age positively to adoption of CA (Okoye 1998), while Clay et al. (1998) and Neill and Lee (2001) found negative and insignificant results, respectively.

Gender is a dummy variable (male $=1$ and 0 otherwise). It is expected that households headed by females tend to have labor constraints and are less likely to adopt CA (Giller et al. 2009).

Total cultivated land is a continuous variable that is anticipated to positively influence adoption and extent of CA. Households with larger farm sizes are more likely to invest in new technologies because they can spread risk.

Education is an ordinal variable $(2=\mathrm{sec}-$ ondary level, $1=$ primary, and $0=$ illiterate) that measures the level of education of head of household. We expect that as education increases so do human capital and monetary resources. As human capital increases, it is more likely that a superior technology will be adopted. In general, education correlates positively with adoption of CA practices (Warriner and Moul 1992).

Family size and dependency ratio are continuous variables that measure the size of the household and family labor availability, respectively. Age dependency ratio is the ratio of dependents (people younger than 15 or older than 64) to the working-age population (those aged 15 to 64 ). We expect that the probability of adoption will increase as human capital increases.

Hired labor is a dummy variable (yes $=1$ and 0 otherwise) that is an indicator of rela- tive wealth in most smallholder settings. It is hypothesized that households with capacity to hire labor are more likely to intensify CA adoption since CA is believed to demand more labor (Giller et al. 2009).

Community labor is a dummy variable (yes $=1$ and 0 otherwise) that is used to identify whether the farmer had been involved in community labor, although it is reciprocal and can contribute to, or be part of, social capital. It is hypothesized that households involved in community labor are more likely to adopt CA due to relief of some labor-demanding tasks of CA.

Membership of farmer group is a dummy variable ( $1=$ yes and 0 otherwise) specifying if a farmer belonged to a farmer association of any kind. The rationale is that a farmer belonging to an association benefits from access to information about potential gains in income and leisure from the use of CA, which can influence the rate of adoption.

District is a proxy of geographical location that is used to describe the biophysical conditions of the study area. The rationale is that adoption is more likely in districts where CA is perceived to address the major biophysical constraints limiting crop productivity in smallholder farms.

Received input subsidy is a dummy variable ( $1=$ yes, and 0 otherwise) that is used to specify if a farmer received subsidized farm inputs from government. Input subsidy is hypothesised to be positively linked to adoption and extent of CA because CA responds more to input use, particularly in the form of fertilizer, than CT.

Tropical livestock unit (TLU) index is a continuous variable (cattle $=0.7$, pigs $=0.2$, sheep and goats $=0.1$, and poultry $=0.01$ ) that provides a convenient method for quantifying a wide range of different livestock types and sizes in a standardized manner (FAO 2002). It is hypothesized that high TLU index indicates more competition for crop residues between CA and livestock feed thereby reducing the likelihood of adoption.

Number of years of practicing CA is hypothesized to influence extent of use of CA. We expect that as the length of time of practicing CA increases (and therefore more knowledge and experiences on CA are gained), the likelihood of allocating more land to CA also increases. 


\section{Results and Discussion}

This section starts with descriptive statistics of explanatory variables used in econometric analysis before it engages in discussion of analysis of factors of adoption and extent of CA. A discussion of the results combines quantitative and qualitative approaches in order to provide a comprehensive analysis of the explanation of the actual mechanisms or contextual factors underpinning the econometric analyses (Carvalho and White 1997).

Descriptive Statistics. Descriptive statistics for the variables used for the analysis are presented in table 3 . About $79 \%$ of the adopters and $78 \%$ of nonadopters were male-headed households. The average age of adopters is 49 and that of nonadopters is 41 , which implies that adopters have more farming experience than nonadopters. The education level is low: $22 \%$ of adopters and $20 \%$ of nonadopters had attended secondary school, $65 \%$ of adopters and $66 \%$ of nonadopters had finished primary school, and $13 \%$ of both adopters and nonadopters were illiterate. Family size for both adopters and nonadopters is 5.7. The dependency ratio of adopters is 0.98 and that of nonadopters is 1.1 . About $60 \%$ of adopters and $31 \%$ of nonadopters hired seasonal labor to augment their labor supplies for the farming operations. The use of community labor is very low, about $9 \%$ for both adopters and nonadopters. Seventy-eight percent of adopters and $72 \%$ of nonadopters received input subsidy. The average farm size is 2.4 ha $(5.9 \mathrm{ac})$ for adopters and that of nonadopters is $1.4 \mathrm{ha}(3.5 \mathrm{ac})$. The study results show that about $93 \%$ of adopters and $5 \%$ of nonadopters belonged to farmer groups. About 35\% of adopters belonged to NGO groups and $25 \%$ belonged to extension groups. The TLU conversion factor was double for adopters (1.0) than for nonadopters (0.5). Forty-five percent of the sampled households in Balaka were adopters, compared with $47 \%$ in Dowa, $25 \%$ in Machinga, $58 \%$ in Nkhotakota, $74 \%$ in Salima, and 53\% in Zomba.

Factors Motivating Farmers to Adopt Conservation Agriculture. We asked adopting farmers to tell us what motivates them to practice CA. Farmers cited higher yields, labor saving, potential soil fertility increase, soil moisture conservation, and soil erosion control as major motivations of CA adoption (figure 2). About $83 \%$ of the adopters mentioned increased yield as one of the key factors that attracted them to CA. Farmers attributed the increase in yields under CA to

\section{Table 3}

Descriptive statistics for variables in the empirical economic models.

\begin{tabular}{llc}
\hline Variables & $\begin{array}{l}\text { Adopters } \\
(\boldsymbol{n}=\mathbf{1 5 1})\end{array}$ & $\begin{array}{l}\text { Nonadopters } \\
(\boldsymbol{n}=\mathbf{1 4 9})\end{array}$ \\
\hline Gender (\%) (1 = male) & 79.0 & 78.1 \\
Age (mean) & 49 & 41 \\
Education level of household head (\%) & & \\
$\quad$ Illiterate (\%) & 13.1 & 13.5 \\
$\quad$ Primary school (\%) & 64.5 & 66.2 \\
$\quad$ Secondary school (\%) & 21.5 & 20.3 \\
$\quad$ Tertiary (\%) & 0.7 & 0.0 \\
Family size & 5.7 & 5.7 \\
Dependency ratio (mean) & 0.98 & 1.1 \\
Hired labour (\%) (1 = Yes) & 59.9 & 31.1 \\
Community labour (\%) (1 =Yes) & 9.2 & 8.8 \\
Total cultivated land (ha) & 2.4 & 1.4 \\
Membership of farmer group (\%) & 92.8 & 4.7 \\
Received input subsidy (\%) (1 = Yes) & 78.3 & 72.3 \\
Tropical livestock unit (TLU) index & 1.0 & 0.5 \\
Balaka (\%) & 45 & 55 \\
Dowa (\%) & 47 & 53 \\
Machinga (\%) & 25 & 75 \\
Nkhotakota (\%) & 58 & 42 \\
Salima (\%) & 74 & 26 \\
Zomba (\%) & 53 & 47
\end{tabular}

effective weed control through use of herbicides and greater soil moisture conservation as a result of retaining an adequate amount of crop residues as surface mulch that enhanced crops' ability to withstand dry spells. About $81 \%$ of the adopters subscribed to the labor-saving abilities of CA. The labor-saving element in CA is primarily due to direct planting in no-tillage and controlling weeds with herbicides. In the CT systems, land clearing, ridging and weed control are achieved through use of hand hoe. Soil fertility benefits, improved soil water conservation, and increased ability of CA to control soil erosion were among ecological factors perceived by farmers to increase maize yields.

Adoption of Different Components of Conservation Agriculture. Crop residue retention as surface mulch and no-tillage were practiced by $97 \%$ and $94 \%$ of the adopters, respectively (figure 3). Compared with other countries of southern Africa, in Malawi, the retention of crop residues as surface mulch appears to be less of a problem; the country's low cattle population does not compete for crop residues as feed. However, during interactive discussion with farmers, it was observed that retention of crop residues as surface mulch could be hampered by fears of termites, rodents hunting, and bushfires; the need for sources of fuel wood and fencing materials; and concerns about sterilizing beds of tobacco nurseries, among others. Herbicides (97\%) and dibble sticks (90\%) were also adopted by farmers. Crop rotation and intercropping were practiced by $27 \%$ and $45 \%$, respectively, of the adopters. Farmers prioritize food security concerns over other farming objectives and hence allocate larger proportions of their landholding to maize than other crops. Farmers also lack access to legume seed and output markets for legume crops. The middlemen buy produce at very low prices, which act as a disincentive to farmers to invest in more balanced cereal-legume rotations or associations - a key component of CA. Smallholder farmers were also integrating agroforestry (29\%) into CA systems.

Extent of Conservation Agriculture Adoption. The land area allocated to CA by adopters increased with time (figure 4). Although the area under CT practices is higher than that of CA, it is important to note that farmers are increasingly embracing CA technologies as evidenced by an upward trend in average area per adopter from 0.1 ha $(0.2 \mathrm{ac})$ in 2004 to 2005 to 0.48 ha $(1.19$ ac) in the 2009 to 2010 cropping seasons. By the 2009 to 2010 season, land area under 


\section{Figure 2}

Motivating factors of conservation agriculture adoption in Malawi. Values add up to more than $100 \%$ due to multiple responses.

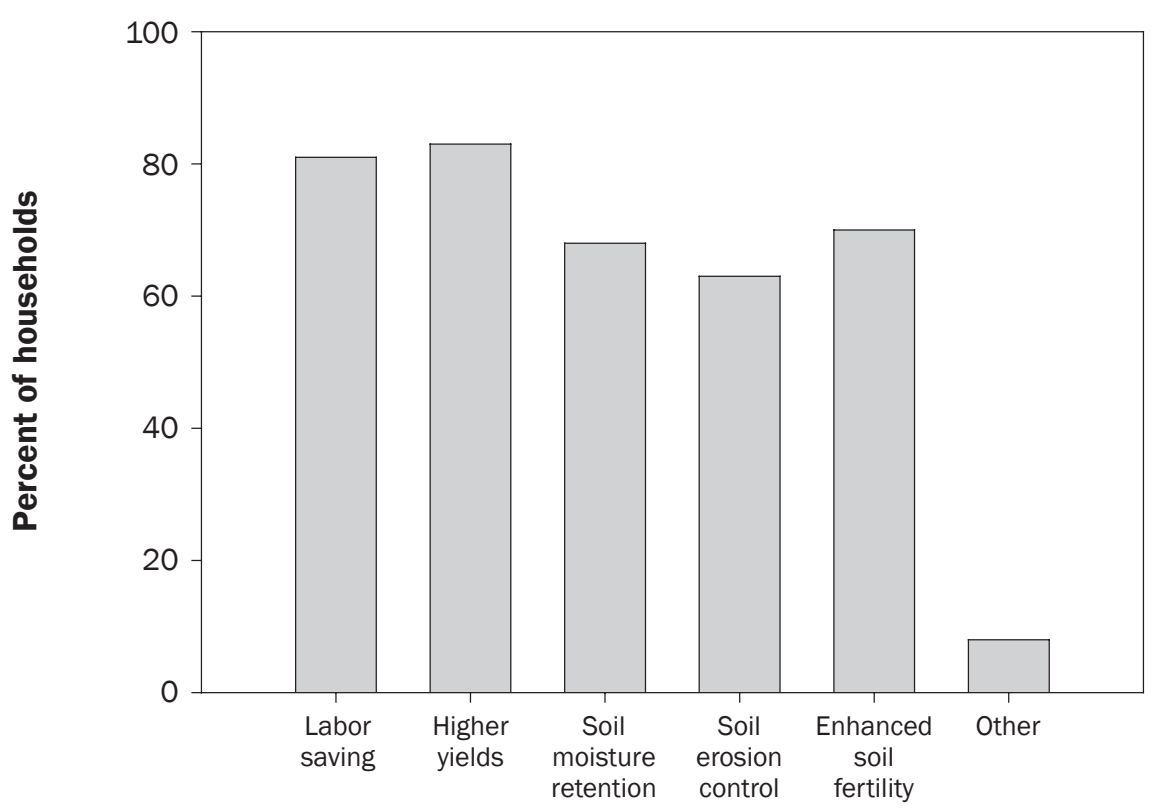

Factors

\section{Figure 3}

Development in use of various conservation agriculture-related practices by adopters with time.

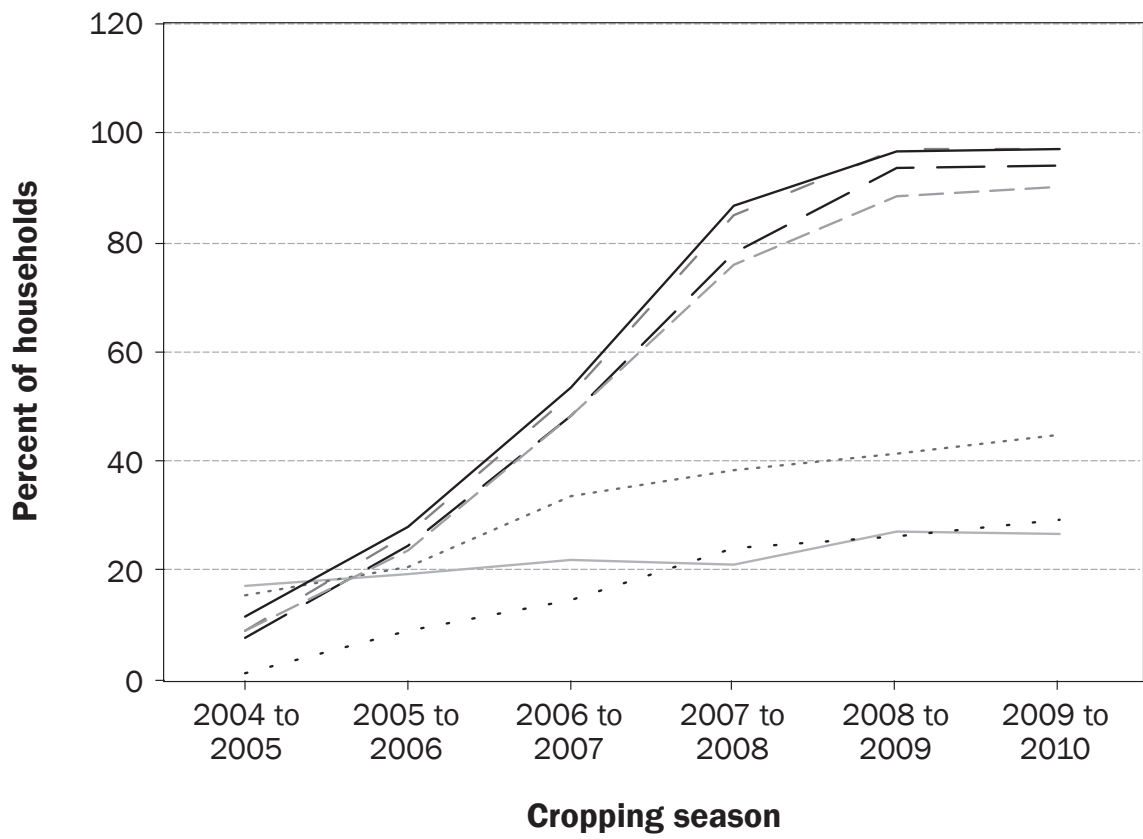

\section{Legend}

CA constituted about $30 \%$ of total cultivated land among adopters. The results confirm the step-wise adoption of CA by smallholder farmers (Thierfelder et al. 2013b).

Reasons for Nonadoption. Farmers who never tried CA mentioned lack of information (70\%) and labor bottlenecks (23\%) as critical in the initial years of CA adoption (figure 5).About 12\% of the respondents had negative perceptions of herbicides, which they thought had negative effects on the soil. About 9\% argued they did not see the need to practice CA.

The Heckman Two-Step Selection Model. We analyzed factors affecting adoption and extent of CA simultaneously using the Heckman two-step model to control for potential selection problems. The results are presented in table 4 . Overall, the model was highly significant as indicated by the Wald Chi-square $(p<0.01)$. The IMR was not significantly different from zero $(p>0.1)$, implying that there was no significant sample selection bias. This does not completely rule out sample selection bias, but it simply means that the sample selection bias available was not significant enough to render OLS estimates inefficient. Thus we could as well estimate the adoption and extent parts of the model separately without affecting the efficiency of the estimates. Indeed, the estimated OLS coefficients yield the same conclusions as the Heckman model.

Factors Affecting Farmers' Conservation Agriculture Adoption Decisions. The first stage of the Heckman model showed that measures of resource endowment in terms of hired labor and area of land cultivated influence farmers' decisions to adopt CA. It further showed that belonging to farmer group and particular district increases the likelihood of adoption of CA (upper part of table 4). Use of hired labor was positive and significant at the $1 \%$ significance level. The results show that more use of hired labor increases the likelihood of adopting CA. The ability to hire labor is an indicator of relative wealth in most smallholder settings. This may imply that hired labor was used on conventionally tilled fields and not necessarily on CA plots since adopters owned larger amount of cultivated land compared with nonadopters. In addition, there is increased demand for labor in CA for residue transfer at least in the initial years as farmers adjust to the new system. CA is also perceived to increase weed population, especially in absence of herbicides, 


\section{Figure 4}

Area allocated to conservation agriculture and conventional tillage practices with time.

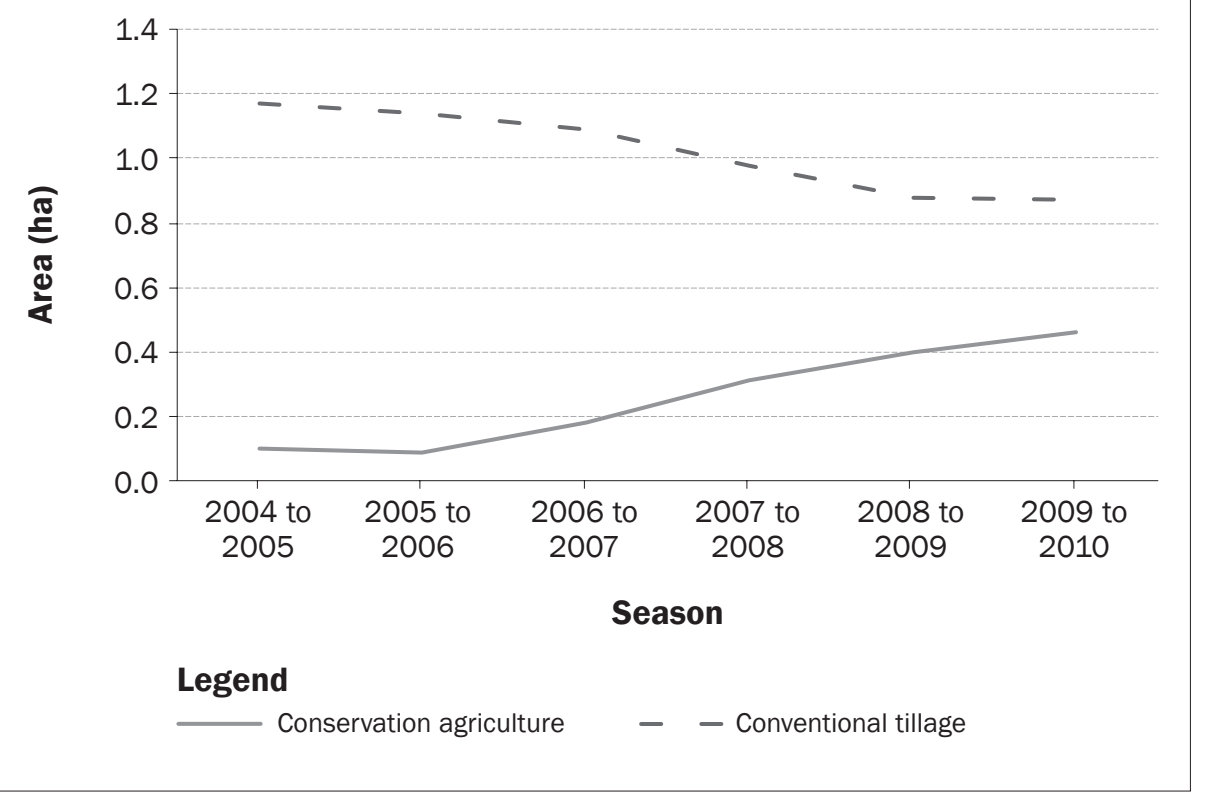

and is therefore regarded as labor-intensive (Giller et al. 2009).

Amount of cultivated land was significant at the $10 \%$ significance level and positively related to likelihood of adoption. This is in line with the findings of Fuglie (1999) and

\section{Figure 5}

Reasons for nonadoption of conservation agriculture.

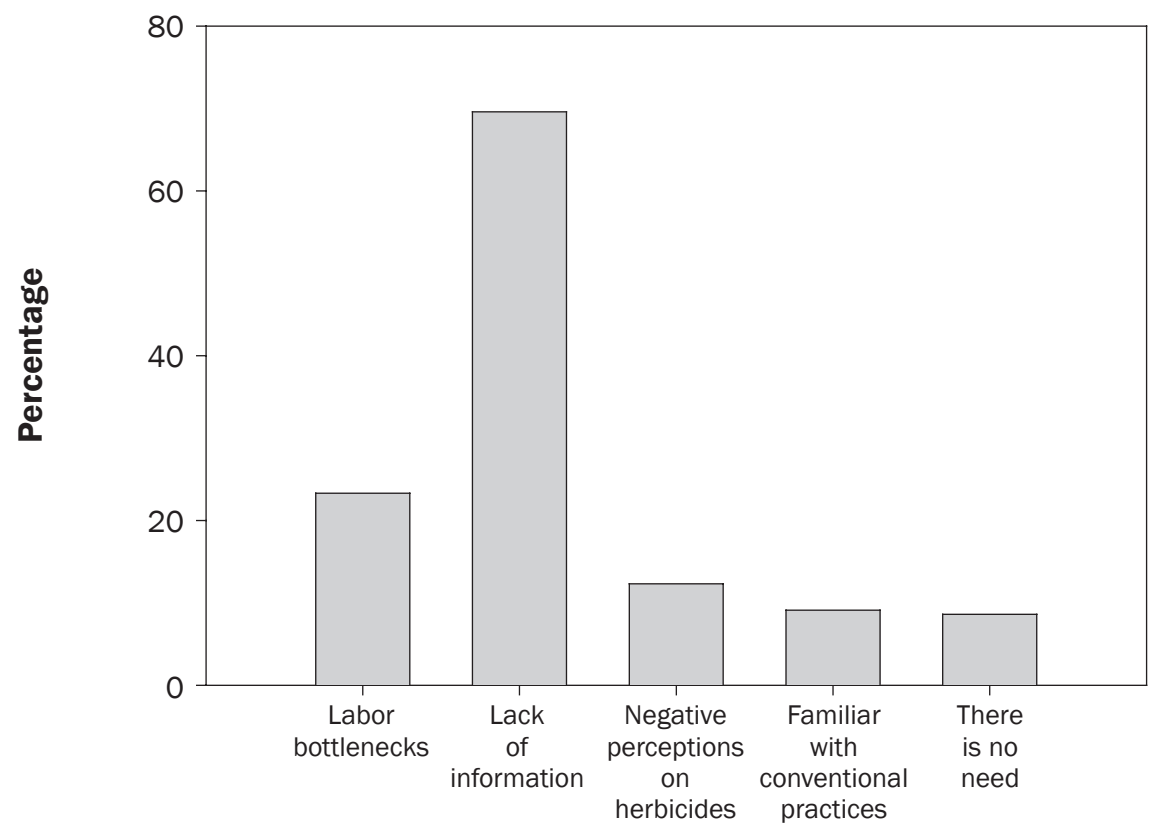

Factors and more ability and willingness to deal with risk and survive crop failure due to pests and/or drought (Nowak 1987). These are in line with economic constraint theoretical perspective that posits that observed patterns of adoption are determined by the asymmetrical distribution of resource endowments among individuals (Adesina and Zinnah 1993; Negatu and Parikh 1999).

We also tested whether location had any influence in CA adoption. We arbitrarily set Zomba to be the basis of our comparison. This was done to avoid what is referred to as dummy trap, i.e., running a model with all districts set as dummies leads to perfect collinearity, which can be avoided by either running the model without the constant term or dropping of the dummy variables, which then act as a basis for interpretation for the remaining dummies. The positive and significant (at 10\% significance level) relationship on Dowa and Nkhotakota districts implies that farmers in these districts are more likely to adopt CA than those in Zomba. The significance of the district dummy variables is explained by unspecified missing factors that were not included in the Heckman model. Such factors include district differences in climate, perception of soil erosion problems, and incentives from farmer organizations, among others. During our interactive discussions with farmers and farmer groups, it was discovered that farmers in the Chipeni community in Dowa district perceive soil erosion to be a problem since their farms are located on a higher altitude (table 1) with steep slopes, erodible soils, perceived hoe pans, and limited natural barriers for protection. CA that includes retention of crop residues as surface mulch is perceived by farmers in Dowa as an effective method to manage soil erosion on their fields, hence motivating a greater tendency to adopt CA than in Zomba.This is in tandem with other studies that have reported positive and significant correlations between steep slopes, high soil erosion, and probability of adoption of CA (Uri 1997; Soule et al. 2000; Pautsch et al. 2001). Indeed, raising farmer awareness and concern for soil erosion is probably one of the critical factors affecting adoption of soil conservation measures. This is in line with adopter-perception theoretical perspective that postulates that the adoption process starts with the perception that there is need to innovate. 


\section{Table 4}

Heckman model of regression of factors affecting farmers' decisions to adopt conservation agriculture (CA) and extent of CA in Malawi.

\begin{tabular}{|c|c|}
\hline Variables & Coefficient \\
\hline \multicolumn{2}{|l|}{ Factors determining $\mathrm{CA}$ adoption } \\
\hline Constant & $-4.998(-3.88) * * *$ \\
\hline Gender & $-0.037(-0.09)$ \\
\hline Age & $0.014(1.20)$ \\
\hline Education & $0.113(0.41)$ \\
\hline Family size & $0.093(1.31)$ \\
\hline Dependency ratio & $0.040(0.29)$ \\
\hline Hired labor & $0.950(2.77)^{* * *}$ \\
\hline Community labor & $-0.379(-0.68)$ \\
\hline Total cultivated land & $0.352(1.88) *$ \\
\hline Membership of farmer group & $3.740(8.98) * * *$ \\
\hline Subsidized fertilizer & $0.029(0.08)$ \\
\hline Tropical livestock unit index & $0.064(0.38)$ \\
\hline Balaka & $0.811(1.05)$ \\
\hline Dowa & $1.289(1.65)^{\star}$ \\
\hline Machinga & $-0.364(-0.49)$ \\
\hline Nkhotakota & $1.270(1.69) *$ \\
\hline Salima & $1.663(1.57)$ \\
\hline \multicolumn{2}{|c|}{ Factors influencing farmers' extent of CA adoption } \\
\hline Constant & $0.224(1.68)$ \\
\hline Family size & $0.002(0.19)$ \\
\hline Dependency ratio & $0.022(0.93)$ \\
\hline Hired labor & $-0.006(-0.12)$ \\
\hline Community labor & $0.057(0.79)$ \\
\hline Total cultivated land & $-0.049(-3.31) * * *$ \\
\hline Subsidized fertilizer & $-0.007(-0.14)$ \\
\hline Tropical livestock unit (TLU) & $-0.017(-1.02)$ \\
\hline Number of years of CA practice & $0.043(2.34) * *$ \\
\hline Balaka & $0.046(0.42)$ \\
\hline Dowa & $0.285(2.72)^{* * *}$ \\
\hline Machinga & $0.075(0.57)$ \\
\hline Nkhotakota & $0.380(3.69) * * *$ \\
\hline Salima & $0.239(1.96)^{*}$ \\
\hline \multicolumn{2}{|l|}{$* p<0.1 * * p<0.05 * * * p<0.01$} \\
\hline $\begin{array}{l}\text { Notes: } n=299 \text {. Wald Chi-square }= \\
\text { Figures in parentheses are } t \text {-values }\end{array}$ & $\mathrm{o}(\mathrm{IMR})=-0.082(-0.61)$ \\
\hline
\end{tabular}

Although Zomba and Nkhotakota receive similar rainfall, the two districts differed in their farming systems, major crops grown, and incentives from farmer organizations. Results of key informant interviews revealed that farmers in Nkhotakota also participate in other farmer associations such as Department for International Development cotton commodity chains that serve to educate farmers about the marketing and cultivation of crops. While cotton associations do not directly support or advocate the use of CA, they do serve as a means by which farmers are able to share information about to and use of herbicides to control weeds was the sole responsibility of farmers. These results are in line with assertions by Naudin et al. (2010) who claimed that farmers in traditional cotton-growing areas of Cameroon had less problems in handling herbicides than their counterparts in Madagascar where pesticide use was uncommon.

Membership in farmer groups was also significant at $1 \%$ and positively correlated with the probability that farmers would adopt CA. Extension workers find it easier to provide information and backup technical support to farmers in groups. Smallholder farmers in farmer groups interact and influence each other over time through socialization processes. There is also informal sharing of knowledge and experiences on CA when farmers belong to a group with similar objectives and interests. To the extent that community organizations provide information on new technologies and training, membership in such groups encourages adoption, perhaps because members in the group become socialized and develop similar norms and preferences, including attitudes and practices concerning farm management over time. Results of key informants indicated that farmers in groups were engaged in labor-sharing arrangements, where farmers worked in sequence from one field to another. This, they explained, helped to rebuild social capital, reciprocity, and altruism. One common case of altruism was where a lead farmer had offered her knapsack sprayer and time to train other farmers in spraying herbicides to control weeds free of charge. With the low extension to farmer ratio in Malawi, use of lead farmers is increasingly seen as one of the ways information is disseminated to farmers, especially through the use of demonstration plots (Wellard et al. 2012). Lead farmers are selected within communities by the farmers themselves with the support of extension workers. Thus they serve as experiential experts in shaping peoples' norms and values and may play a role in legitimizing or disapproving particular changes. The key informants explained that lead farmers through hosting demonstration plots played the role of extension workers in training other farmers in CA agronomic practices. Extension workers explained that some farmers adopted CA following successful implementation of CA by lead farmers. Other studies have also shown the positive and significant relationship between 
adoption of CA and membership in farmer organizations (Sidibé 2005; Knowler and Bradshaw 2007). Membership in community groups was one of the reported variables associated with reducing risk and uncertainty of agroforestry technologies (Mercer and Pattanayak 2003). This is in tandem with social learning theory that postulates that people learn by observing the behaviour of others (Bandura 1977).

Our study finds that membership in farmer groups is one of the most significant variables in determining a household's probability of adopting CA. Although hypothesized differences between districts in terms of climate and farmer perceptions of the problem of soil erosion could significantly account for farmers adoption of CA, our discussion with key informants coupled with field observations revealed that adopters in Dowa, Nkhotakota, and Salima belonged to NGO groups organized by TLC, while farmers in Balaka, Machinga and Zomba belonged to groups organized by public extension workers. Membership in an NGO group influenced the adoption of CA in two ways. One is that farmers had access to revolving fund initiatives that facilitated purchase of inputs such as herbicides and maize and grain legume seed. Handling of revolving fund programs is limited to the private sector in Malawi. The second way NGO group membership influenced adoption was related to access to information by smallholder farmers. Key informant interviews revealed that participatory technology development involving TLC enabled more support and delivery of information that could not be achieved using the linear model of technology development (research-extension-farmer linkages). Field staff in TLC had specific targets set by their management each year that forced them to work hard in conducting trainings with farmers. Respondents reported that having more training sessions enhanced their capacity and confidence to conduct CA.TLC as an NGO received some more funds that enabled them to hire International Maize and Wheat Improvement Centre scientists to specifically train their field staff in agronomic practices of CA. With this high level of funding, TLC field staff engaged farmers in field days and farmer-to-farmer exchange visits in addition to the annual field tours organized by the project. Informal discussions with farmers and farmer groups indicated that there has been increased contact between farmers and field staff. Provision of training to farmers with practical, useful answers that assist them in their day-to-day operations is important in enhancing adoption of new innovations (Vanclay 2011). It is not surprising that most farmers in districts where TLC operates had adopted CA.This is in tandem with diffusion of innovation theory that posits information dissemination central to adoption of innovation (Rogers 2003). On the other hand, government extension officers receive less funding from the government and are also highly engaged in the government led farm input subsidy program as well as crop estimates activities that consume a significant part of their time at the expense of other activities related to agricultural development.

Factors Affecting Farmers' Extent of Conservation Agriculture Adoption. Having assessed the factors that determine CA adoption in the first stage, the second stage of the Heckman model assesses the determinants of extent of CA adoption (lower part of table 4). Total cultivated land, duration of practicing CA, and district significantly influence farmers' extent of CA adoption. Extent is measured by the amount of land allocated to CA relative to total cultivated land per household. Total cultivated land was significant at the $1 \%$ significance level and negatively influenced farmers' decisions in extending their land to CA practices. However, extent was measured as the proportion of land under CA divided by total cultivated land used by the farmer. This means, holding other things constant, the bigger the total land, the lesser the extent. A test of correlation between absolute CA land allocation and extent was positive and significant $(p<0.05)$ suggesting that the more available land in total, the more land is allocated to CA, but the more land the lower share.

The length of time that farmers have practiced CA in their district had a positive and significant (5\% significance level) impact on land under CA. The possible explanation for this could be as the number of years of practicing CA increases and more knowledge and experiences are gained on CA, the likelihood of allocating more land to CA increases, as farmers respond to yield gains, labor savings, and soil quality improvement (figure 2). These findings are consistent with the role of information and learning in a framework of role of risk, uncertainty, and learning in adoption of agricultural technology (Marra et al. 2003).
Dowa, Nkhotakota, and Salima districts are positive and significant suggesting that farmers living in these districts are more likely to extend their land to CA than those in Zomba district. Average landholding size of farmers in Dowa, Nkhotakota, and Salima is higher than in Zomba. Farmers with limited landholding sizes will allocate less land to CA because they are more risk averse in the wake of prioritizing food security concerns.

In addition, adopters in Dowa, Nkhotakota, and Salima are members of NGO groups and therefore face different economic realities than those in public extension groups, realities that are taken into account in their practical adaptations and experiences. As already illustrated above, CA was perceived to save labor, especially when herbicides are used to control weeds, and the more area under CA, the more labor saved which potentially could be used for other enterprises. Farmers in Dowa reported to have used the labor saved to grow horticultural crops such as paprika, tomato, and vegetables with the assistance of TLC staff. Farmers in Nkhotakota and Salima reported that they allocate more land to CA in order to use the saved labor to grow other crops such as cotton, groundnuts, paprika, etc.

\section{Summary and Conclusions}

Adoption of CA systems was assessed in central and southern Malawi in 2010 using a household questionnaire, key informant interviews, field observations, and a literature review. The study was conducted in 10 communities to account for differences in agroecologies and advisory support services provided to farmers to better understand the adoption process. The Heckman model of CA was used to estimate both dichotomous (discrete) data and the continuous stage to tackle the extent of adoption. This approach differed to that used in other studies, which typically estimate dichotomous data models on a divisible technology without estimating extent of adoption. Key informant interviews and discussions with farmers and farmer groups provided information on actual mechanisms underpinning the statistical relationships found by the Heckman model.

The findings of this study suggest that membership to farmer groups, resource endowment (hired labor and total land cultivated), and district play an important role in shaping adoption and extent of CA, presenting a unique set of challenges for farmers in 
this region. Membership to an NGO group appeared the most important factor influencing adoption and extent of CA. Public extension workers remain the prime agents of promoting agricultural technologies in Malawi using linear model of research-extension-farmer linkage, and the study results reveal that these change agents are not provided with adequate resources necessary to facilitate CA adoption. In absence of NGO support in facilitating farmers' access to key agricultural inputs, there is need to encourage participation of local agrodealers in providing inputs and information that are necessary for farmers practicing CA. Government extension staff should be fully supported in terms of resources to enable them reach a wider audience of smallholder farmers if extensive adoption of CA is to be realized. Hence, without proper farmer training and group formation, farmers are likely to experience slow adoption of CA.

Where landholding sizes are small, CA has a difficult agronomic hurdle to overcome since it must either overcome the farmers' food security concerns often associated with allocating large fields if not all of their fields to monocropped maize or incur an opportunity cost of allocating some part of their land to crop rotations (one of the principles of CA) that provide less staple foods. This study finds total cultivated land to negatively influence farmers' decisions in extending their land to CA practices, suggesting that the more available land in total, the more land is allocated to CA. However, the more land, the lower the share allocated. An interesting study in future would be to investigate whether the pattern would be the same as CA adoption extent increases, i.e., whether the extent of adoption would remain negatively associated with land size or not. One possible hypothesis is that there would be a U-shaped relationship between CA extent and land size, i.e., extent would first decrease with land size (the current result) but then would increase with land size once CA becomes more viable and attractive to farmers. On the other hand, another scenario would be that farmers would perceive CA as not attractive, in which case they would simply maintain the current CA plots or even decrease their areas. In that case, one would expect the coefficients to remain negative.

The number of years that the household has practiced CA proved to be an important factor in the extent of adoption, which indi- cates that once CA is adopted, farmers are likely to increase the extent to which it is practiced throughout the years. The increase in the allocation of land to CA with duration of CA practice demonstrates the value of being able to observe CA adoption as a dynamic process that occurs over a long period as farmers experiment with CA and incorporate it into their farming systems.

The study contributes to proposition of strong institutional support in increasing knowledge and awareness of CA and the choices of different mixed cropping systems, which needs to be addressed by policy makers. Improved knowledge and awareness of $\mathrm{CA}$ and continued farmer support could be the most cost effective way to increase CA adoption, particularly since the study found that farmers consider lack of information and associated provisional services the most important reasons for not adopting CA in their production systems. These results point to the importance of skills and capabilities of lead farmers and field staff in the application of the principles of CA. The results further suggest that adoption of new innovation takes place in a social context as farmers learn by observing what significant persons in society are doing. Extension and outreach activities should be able to provide farmers with up to date information through traditional field days, farmer-to-farmer exchange visits, informal farmer-to-farmer interactions, and workshops.

\section{Acknowledgements}

We would like to thank the anonymous reviewers for their meaningful comments that have greatly shaped the paper in its current form. Special thanks go to Thabbie Chilongo a $\mathrm{PhD}$ student at the Norwegian University of Life Sciences, School of Economics and Business in Aas, Norway, for his guidance in data analysis. We wish to thank Vine Mutyasira, a research associate for the International Maize and Wheat Improvement Centre (CIMMYT), and Mphatso Gama, a crops officer for Machinga Agricultural Development Division, for their direct involvement in the training and supervision of enumerators and key informants and farmers for their responses during the study. We would like to express our gratitude to Total Land Care and Agricultural Research and Development Programme (ARDEP) through the Royal Norwegian Embassy for partially funding the survey. We wish to acknowledge the CIMMYT for logistical and financial support and the German Technical Cooperation (GTZ) and International Fund for Agricultural Development (IFAD) for funding project activities.

\section{References}

Adesina, A.A., and M.M. Zinnah. 1993. Technology Chracteristics, farmers' perceptions and adoption decisions: A Tobit Model application in Sierra Leone. Agricultural Economics 9:297-310.

Bandura, A. 1977. Social learning theory. Englewood Cliffs, NJ: Prentice Hall.

Berger, P.L., and T. Luckmann. 1967. The social construction of reality: A treatise in the sociology of knowledge. London: Penguin.

Blevins, R.L., R. Lal, J.W. Doran, G.W. Langdale, and W.W. Frye. 1998. Conservation tillage for erosion control and soil quality. In Advances in Soil and Water Conservation, eds. FJ. Pierce and W.W. Frye. Chelsea: Ann Arbor Press.

Bolliger, A., J. Magid, T.C. Amadon, F.S. Neto., M.D.D. Ribeiro, A. Calegari, R. Ralisch and A. de Neergaard. 2006. Taking stock of the Brazilian "zero-till revolution": A review of landmark research and farmers' practice. Advanced Agronomy 91:47-100.

Bolliger, A.M. 2007. Is zero-till and appropriate agricultural alternative for disadvantaged smallholders of South Africa? A study of surrogate systems and strategies, smallholder sensitivities and soil glycoproteins. $\mathrm{PhD}$ thesis, University of Copenhagen.

Carvalho, S., and H. White. 1997. Combining the Quantitative and Qualitative Approaches to Poverty Measurement and Analysis: The Practice and the Potential. World Bank.

Caviglia, J.L., and J. R. Kahn. 2001. Diffusion of sustainable agriculture in the Brazilian tropical rain forest:A discrete choice analysis. Economic Development and Cultural Change 49(2):311-333.

Clay, D., T. Reardon, and J. Kangasniemi. 1998. Sustainable intensification in the highland tropics: Rwandan farmers'investments in land conservation and soil fertility. Economic Development and Cultural Change 46(2):351-377.

Derpsch, R.2002. Making conservation tillage conventional, building a future on 25 years of research: Research and extension perspective. In Proceedings of 25th Annual Southern Conservation Tillage Conference for Sustainable Agriculture, ed. E.V. Santen. Auburn, AL, USA: Alabama Agricultural Experiment Station, Auburn University.

Derpsch, R., T. Friedrich, A. Kassam, and L. Hongwen. 2010. Current status of adoption of no-till farming in the world and some of its main benefits. International Journal of Biological Engineering 3:1-25.

Douthwaite, B. 2002. Enabling Innovation: A practical guide to understanding and fostering technological change. In ZED Books. London: ZED Books.

Ekboir, J.M. 2003. Research and technology policies in innovation systems: Zero tillage in Brazil. Research Policy 32(4):573-586.

FAO (Food and Agriculture Organization of the United Nations). 2002. Tropical Livestock Units (TLU). http:// www.fao.org/ag/againfo/programmes/en/lead/ toolbox/Mixed1/TLU.htm.

FAO. 2013. What is Conservation Agriculture? http://www. fao.org/ag/ca/1a.html.

Feder, G., R.E. Just, and D. Zilberman. 1985. Adoption of agricultural innovations in developing countries: A 
survey. Economic Development and Cultural Change 33(2): 255-298.

Fuglie, K.O. 1999. Conservation tillage and pesticide use in the cornbelt. Journal of Agricultural and Applied Economics 31(1):133-147.

Giller, K.E., E. Witter, M. Corbeels, and P. Tittonell. 2009. Conservation agriculture and smallholder farming in Africa: The heretics' view. Field Crops Research 114(1):23-34.

Gowing, J.W., and M. Palmer. 2008. Sustainable agricultural development in sub-Saharan Africa: The case for a paradigm shift in land husbandry. Soil Use and Management 24(1):92-99.

Hall, A., V. Rasheed Sulaiman, N. Clark, and B. Yoganand. 2003. From measuring impact to learning institutional lessons: an innovation systems perspective on improving the management of international agricultural research. Agricultural Systems 78(2):213-241.

Heckman, J.J. 1979. Sample selection bias as a specification error. Econometrica, 47(1):153-161.

Hobbs, P.R., K. Sayre, and R. Gupta. 2008. The role of conservation agriculture in sustainable agriculture. Philosophical Transactions of the Royal Society B 363:543-555.

Ito, M., T. Matsumoto, and M.A. Quinones. 2007. Conservation tillage practice in sub-Saharan Africa:The experience of Sasakawa Global 2000. Crop Protection 26:417- 423

Kassam, A., T. Friedrich, F. Shaxson, and J. Pretty. 2009. The spread of Conservation Agriculture: Justification, sustainability and uptake. International Journal of Agricultural Sustainability 7(4):292-320.

Knowler, D., and B. Bradshaw. 2007. Farmers' adoption of conservation agriculture: A review and synthesis of recent research. Food Policy 32(1):25-48.

Lal, R. 2009. The plow and agricultural sustainability. Journal of Sustainable Agriculture 33(1):66-84.

Leeuwis, C., and A.W.v.d. Ban. 2004. Communication for rural innovation: Rethinking agricultural extension. Oxford: Blackwell Science.

Lohr, L., and T.A. Park. 1995. Utility-consistent discretecontinuous choices in soil conservation. Land Economics 71(4):474-490.

Long, N., and A. Long. 1992. Battlefields of knowledge: the interlocking of theory and practice in social research and development. London: Routledge.

Lynne, G.D., J.S. Shonkwiler, and L.R. Rola. 1988. Attitudes and farmer conservation behavior. American Journal of Agricultural Economics 70(1):12-19.

Marongwe, L.S., K. Kwazira, M. Jenrich, C. Thierfelder, A. Kassam, and T. Friedrich. 2011. An African success: The case of conservation agriculture in Zimbabwe. International Journal of Agricultural Sustainability 9(1):153-161.

Marra, M., D.J. Pannell, and A. Abadi Ghadim. 2003. The economics of risk, uncertainty and learning in the adoption of new agricultural technologies: Where are we on the learning curve? Agricultural Systems 75(2-3):215-234

Mercer, D.E., and S.K. Pattanayak. 2003. Agroforestry adoption by smallholders. In Forests in a Market Economy, eds. E. Sills and K. Abt. Forestry Sciences
Series 283-299. Dordrecht, The Netherlands: Kluwer Academic Publishers.

Mwaseba, D.L., R. Kaarhus, F.H. Johnsen, Z.S.K. Mvena, and A.Z. Matte. 2006. Beyond adoption/rejection of agricultural innovations. Outlook on Agriculture 35(4):263-272.

Naudin, K., E. Gozé, O. Balarabe, K.E. Giller, and E. Scopel. 2010. Impact of no tillage and mulching practices on cotton production in North Cameroon: A multilocational on-farm assessment. Soil and Tillage Research 108(1-2):68-76

Negatu, W., and A. Parikh. 1999. The impact of perception and other factors on the adoption of agricultural technology in the Moret and Jiru Woreda of Ethiopia. Agricultural Economics 21:205-216.

Neill, S.P., and D.R. Lee. 2001. Explaining the adoption and disadoption of sustainable agriculture: The case of cover crops in northern Honduras. Economic Development and Cultural Change 49(4):793-820.

Ngwira, A.R., C. Thierfelder, and D.M. Lambert. 2013 Conservation agriculture systems for Malawian smallholder farmers: Long-term effects on crop productivity, profitability and soil quality. Renewable Agriculture and Food Systems 28:350-363. http:// dx.doi.org/10.1017/S1742170512000257.

Nkala, P., N. Mango, and P. Zikhali. 2011. Conservation agriculture and livelihoods of smallholder farmers in central Mozambique. Journal of Sustainable Agriculture 35(7):757-779

Nowak, P.J. 1987. The adoption of agricultural conservation technologies: Economic and diffusion explanations. Rural Sociology 52(2):208-220.

Okoye, C.U. 1998. Comparative analysis of factors in the adoption of traditional and recommended soil erosion control practices in Nigeria. Soil and Tillage Research 45(3-4):251-263

Pautsch, G.R., L.A. Kurkalova, B.A. Babcock, and C.L. Kling. 2001. The efficiency of squestering carbon in agricultural soils. Contemporary Economic Policy 19(2):123-134

Prager, K., J. Schuler, K. Helming, P. Zander, T. Ratinger, and K. Hagedorn. 2011. Soil degradation, farming practices, institutions and policy responses: An analytical framework. Land Degradation \& Development 22(1):32-46.

Rahm, M.R., and W.E. Huffman. 1984. The adoption of reduced tillage: The role of human capital and other variables. American Journal of Agricultural Economics 66(4):405-413

Rockström, J., P. Kaumbutho, J. Mwalley, A.W. Nzabi, M. Temesgen, L. Mawenya, J. Barron, J. Mutua, and S. Damgaard-Larsen. 2009. Conservation farming strategies in East and Southern Africa: Yields and rain water productivity from on-farm action research. Soil and Tillage Research 103(1):23-32.

Rogers, E.M. 2003. Diffusion of innovations, 5th ed. New York: Free Press.

Röling, N. 2002. Beyond the aggregation of individual preferences: Moving from multiple to distributed cognition in resource dilemmas. In Wheelbarrows Full of Frogs, eds. C. Leeuwis and R. Pyburn, 25-48. Koninklijke Van Gorcum BV.
Sidibé, A. 2005. Farm-level adoption of soil and water conservation techniques in northern Burkina Faso. Agricultural Water Management 71(3):211-224.

Soule, M.J., A. Tegene, and K.D.Wiebe. 2000. Landtenure and the adoption of conservation practices. American Journal of Agricultural Economics 82(4):993-1005.

Thierfelder, C., J.L. Chisui, M. Gama, S. Cheesman, Z.D. Jere, W.T. Bunderson, N.S. Eash, and L.Rusinamhodzi. 2013a. Maize-based conservation agriculture systems in Malawi: Long-term trends in productivity. Field Crops Research 142(0):47-57.

Thierfelder, C., T. Mombeyarara, N. Mango, and L. Rusinamhodzi. 2013b. Integration of conservation agriculture in smallholder farming systems of southern Africa: Identification of key entry points. International Journal of Agricultural Sustainability 1-14.

Tosakana, N.S.P., L.W. Van Tassell, J.D. Wulfhorst, J. Boll, R. Mahler, E.S. Brooks, and S. Kane. 2010. Determinants of the adoption of conservation practices by farmers in the Northwest Wheat and Range Region. Journal of Soil and Water Conservation 65:404-412, doi:10.2489/ jswc.65.6.404.

Uri, N.D. 1997. Conservation tillage and input use. Environmental Geology 29(3-4):188-201.

Vanclay, F. 2011. Social principles for agricultural extension in facilitating the adoption of new practices. In Changing Land Management: Adoption of New Practices by Rural Landholders, eds. D. Panell and F. Vanclay, 51-68. Collingwood: CSIRO.

Wall, P. 2007.Tailoring conservation agriculture to the needs of small farmers in developing countries: an analysis of issues. Journal of Crop Improvement 19:137-155.

Warriner, G.K., and T.M. Moul. 1992. Kinship and personal communication network influences on the adoption of agriculture conservation technology. Journal of Rural Studies 8(3):279-291.

Wellard, K., J. Rafanomezana, M. Nyirenda, M. Okotel, and V. Subbey. 2012. A review of community extension approaches to innovation for improved livelihoods in Ghana, Uganda and Malawi. The Journal of Agricultural Education and Extension 19(1):21-35

WRB (World Reference Base). 1998. World reference base on soils. Rome, Italy: Food and Agriculture Organization of the United Nations, International Soil Reference and Information Centre. 